\title{
A pilot study to assess the safety and usefulness of combined transurethral endoscopic mucosal resection and en-bloc resection for non-muscle invasive bladder cancer
}

Yasushi Hayashida ${ }^{1}$, Yasuyoshi Miyata ${ }^{2 *}$ (D), Tomohiro Matsuo ${ }^{2}$, Kojiro Ohba ${ }^{2}$, Hideki Sakai ${ }^{2}$, Mitsuru Taba ${ }^{3}$, Shinji Naito ${ }^{3}$ and Keisuke Taniguchi ${ }^{1}$

\begin{abstract}
Background: Transurethral resection (TUR) is the standard operation used for non-muscle invasive bladder cancer (NMIBC). Although most solid tumors are principally removed via single block resection without incising the mass, disruption of the lesion is unavoidable in traditional TUR. Furthermore, pathological diagnosis is often difficult due to heat-related denaturation of tissues in TUR. Although transurethral en-bloc resection is useful for judging tumor invasion, it is associated with a prolonged operative duration. We attempted to show the safety and usefulness of combined endoscopic mucosal resection (EMR) and en-bloc resection in NMIBC patients.
\end{abstract}

Methods: We investigated 39 patients with clinical NMIBC who were treated using our original EMR + en-bloc resection technique, which involved removal of the tumor mass that protruded from the mucosa, using a polypectomy snare similar to that used for EMR. The residual lesion was removed using en-bloc resection. The operative period, duration of hospitalization, and recurrence rates were compared with those of conventional TUR $(n=31)$.

Results: The mean (standard deviation, range) time interval for EMR and total operative duration were $1.6(1.1,1-5) \mathrm{min}$ and $18.3(10.5,3-48) \mathrm{min}$, respectively. The total operative duration was comparable to that of TUR $(17.3 \mathrm{~min}, p=0.691)$. The mean duration of catheterization in the EMR + en-bloc resection group (4.2 days) was also similar to that in the TUR group (3.7 days; $p=0.285$ ). No severe complications were observed with EMR + en-bloc resection. The pathologists were able to determine tumor invasiveness with considerable certainty in all specimens obtained via the EMR + en-bloc procedure than via TUR, and the difference in the ease of diagnosis was statistically significant $(p=0.016)$. Recurrence rates were comparable ( $p=0.662)$ between the EMR + en-bloc (15.4\%) and TUR groups (19.4\%).

Conclusions: Our results demonstrated that the EMR + en-bloc resection technique is feasible, safe, and useful for treating patients with NMIBC. Furthermore, this technique helps provide a more accurate pathological diagnosis.

Keywords: Endoscopic mucosal resection, En-bloc resection, Non-muscle invasive bladder cancer, Safety, Outcome

\footnotetext{
*Correspondence: int.doc.miya@m3.dion.ne.jp

${ }^{2}$ Department of Urology, Nagasaki University Graduate School of Biomedical

Sciences, 1-7-1 Sakamoto, Nagasaki 852-8501, Japan

Full list of author information is available at the end of the article
}

(c) The Author(s). 2019 Open Access This article is distributed under the terms of the Creative Commons Attribution 4.0 International License (http://creativecommons.org/licenses/by/4.0/), which permits unrestricted use, distribution, and reproduction in any medium, provided you give appropriate credit to the original author(s) and the source, provide a link to the Creative Commons license, and indicate if changes were made. The Creative Commons Public Domain Dedication waiver (http://creativecommons.org/publicdomain/zero/1.0/) applies to the data made available in this article, unless otherwise stated. 


\section{Background}

Bladder cancer (BC) is one of the most common urological malignancies in men [1]. Approximately 75-85\% of newly diagnosed malignancies that are limited to the bladder mucosa or submucosa are classified as nonmuscle invasive bladder cancers (NMIBCs) [2]. Transurethral resection (TUR) remains the gold standard for the treatment of NMIBC. The choice of a radical resection procedure is an important determinant of the outcome in patients with NMIBC. In addition, reaching an accurate diagnosis, especially in the pathologic stage (pT), is important to choose appropriate treatment strategies in these patients. Furthermore, an accurate histopathological diagnosis leads to reduction of overall treatment costs, because an unnecessary second TUR procedure or adjuvant intra-vesical therapy is avoided. Thus, the goal of TUR in early BC is to completely excise visible masses and obtain tissues for an accurate pathological diagnosis of the tumor.

Although TUR is an established and traditional treatment approach, it has various disadvantages. An accurate pathological diagnosis is often difficult because the tumor is removed piecemeal, and the extracted specimens often show morphological changes due to heat denaturation and tissue shrinkage caused by high energy of the resection loop [3, 4]. In addition, some specimens are rendered inadequate due to disorientation and absence of the detrusor muscle tissue. Moreover, although progression rate of NMIBC is relatively low, some researchers are of the opinion that the high number of exfoliated and scattered cancer cells produced during TUR, could lead to metastasis and recurrence due to subsequent seeding and re-implantation [5].

The oncological principle for almost all solid cancers the removal of the tumor via single block resection without incising and cutting into the mass. However, disturbing the tumor mass is unavoidable in traditional TUR. To solve these problems, an 'en-bloc' resection technique was suggested $\sim 20$ years ago [6]. Currently, there is a general agreement that en-bloc resection of bladder tumors is useful and safe for treating patients with NMIBC [7]. However, an international guideline on NMIBC recommends that only small-sized tumors (defined as those with a diameter $<1 \mathrm{~cm}$ ) can be resected en-bloc [8]. In addition, en-bloc resection may require a prolonged operative duration, and an appropriate line of resection can be missed due to bleeding associated with large-sized tumors. Thus, en-bloc resection is not usually employed in patients with relatively large tumors.

Endoscopic mucosal resection (EMR) is a well-defined technique used for the operative removal of gastrointestinal masses. EMR has been used to extract precancerous polyps, early-stage malignant lesions in the esophagus and colon, and gastric cancer lesions. Recently, EMR has been reportedly utilized to remove large lesions in the gastrointestinal tract [9].

Therefore, we paid special attention to EMR for the operative treatment of $\mathrm{BCs}$, especially the large-sized tumors. We hypothesized that performing EMR for the raised portion of a $\mathrm{BC}$ lesion can shorten the operative time required for subsequent en-bloc resection in patients with NMIBCs. To test this hypothesis, we investigated the operative time period and duration of both catheterization and hospitalization required, while using the EMR + en-bloc resection technique to treat patients with NMIBCs. In addition, we compared the measures of these variables to those associated with a conventional TUR procedure.

\section{Methods \\ Patients}

We received approval for the protocol (including the indication for patient selection), from the institutional review board of the National Hospital Organization Ureshino Medical Center to perform the EMR + en-bloc resection technique in selected patients, and to evaluate occurrence of complications, patient outcomes, and pathological diagnoses in those who were operated using either the combination technique or TUR. Written informed consent was obtained from all patients included in the study. In our hospital, while conventional TUR is performed as a standard procedure for the removal of all tumours diagnosed as NMIBC, en-bloc resection (without EMR) is utilized in patients with $\leq 3$ lesions, each with diameter $<1.5 \mathrm{~cm}$. In this study, we hypothesized that EMR may help reduce the operative duration required for the removal of relatively larger tumours. Therefore, we decided to include bladder tumour diameter $\geq 1.5$ $\mathrm{cm}$ as the indication for our EMR + en-bloc method. The institutional review board permitted the employment of EMR + en-bloc operative method in patients with $\leq 3$ tumours of diameters $\geq 1.5 \mathrm{~cm}$, with prior detailed informed consent taken from the concerned patients. Therefore, we provided patients meeting the selection criteria, with in-depth information regarding both EMR + enbloc and conventional TUR techniques including the surgical method, advantages, predictable complications, and cost of each technique. The combined surgical approach was finally chosen after exhaustive consultations with each selected patient and family, in accordance with the rules established by the institutional review board. Consequently, 39 patients finally underwent the EMR + en-bloc resection between January 2013 and December 2017.

However, for a comparative study of the clinicopathological features, we retrospectively collected and analyzed data of those bladder cancer patients, who underwent TUR and had $>3$ tumors, with diameters $<1.5 \mathrm{~cm}$ or $>6 \mathrm{~cm}$ (the diameter of the largest mass operated using the 
combination technique). Finally, we included data of 80 patients, who underwent TUR for NMIBC without metastasis (diagnosed clinically), in this study. Those who received neo-adjuvant chemo- and radiotherapy were excluded. The baseline clinicopathological features of these patients at the time of the operation are shown in Table 1. Although this study is not a randomized clinical trial, we found no significant differences in the clinicopathological characteristics between the participants included in the EMR + en-bloc and the TUR groups (Table 1). Patients included in both groups received prophylactic antibiotics (e.g., cephalosporins) pre- and postoperatively.

\section{Surgical technique}

Sequential images describing the EMR + en-bloc resection are shown in Fig. 1. Firstly, a section of the target tumor mass protruding from the mucosa, was incised using a polypectomy snare (CAPTIVATOR II, Boston Scientific, Marlborough, MA, USA), similar to the one used in EMR [10]. Along with the polypectomy snare, we also used the monopolar ERBE VIO 300D (Endo Cut Effect 2, Tubingen, Germany) electrosurgical device to perform EMR. However, in this step, our method differed from that used for conventional EMR because, we did not inject a fluid or a gel into the submucosal layer, since pooling of the injected substance in the submucosal region is

Table 1 Clinicopathological features at operation

\begin{tabular}{|c|c|c|c|}
\hline & EMR + en bloc & TUR & $P$ value \\
\hline & $n=39$ & $n=31$ & \\
\hline Gender & & & 0.591 \\
\hline Male & $24(61.5)$ & $21(67.7)$ & \\
\hline Female & $15(38.5)$ & $10(32.3)$ & \\
\hline Tumour & & & 0.148 \\
\hline Primary & $36(92.3)$ & 25 (80.6) & \\
\hline Recurrent & $3(7.7)$ & $6(19.4)$ & \\
\hline Location of main tumour & & & 0.879 \\
\hline Lateral & $14(35.9)$ & $13(41.9)$ & \\
\hline Posterior & $13(33.3)$ & $9(29.0)$ & \\
\hline Dome & $7(17.9)$ & $4(12.9)$ & \\
\hline Trigone & $5(12.8)$ & $5(16.1)$ & \\
\hline Pathological grade & & & 0.896 \\
\hline Grade 1 & $12(30.8)$ & $10(32.3)$ & \\
\hline Grade 2 & $19(48.7)$ & 16 (51.6) & \\
\hline Grade 3 & $8(20.5)$ & $5(16.1)$ & \\
\hline Pathological T stage & & & 0.915 \\
\hline Ta & 19 (48.7) & $16(51.6)$ & \\
\hline $\mathrm{T} 1$ & $18(46.2)$ & $14(45.2)$ & \\
\hline $\mathrm{T} 2$ & $2(5.1)$ & 1 (3.2) & \\
\hline
\end{tabular}

EMR endoscopic mucosal resection, TUR transurethral resection difficult due to the anatomical characteristics of the bladder wall [11]. If the tumor was too large to be resected with a single application of the snare, it was used once more to flatten the residual tumor or mucosal tissue. Subsequently, a circular incision was created around the residual lesion using a T-shaped electrode needle TUR-insaline system (Olympus ${ }^{\circ}$, Tokyo, Japan), while maintaining a distance of approximately $5-10 \mathrm{~mm}$ from the tumor edge, for subsequent en-bloc resection, similar to the technique employed for endoscopic submucosal dissection of superficial gastrointestinal tumors [12].

In the control group, conventional TUR was performed in 31 NMIBC patients, who were matched with those in the study group, based on factors including tumor diameter and clinical stage. An intravesical instillation of anthracycline antibiotics was performed in these patients in the immediate postoperative period, to prevent the tumor from spreading. Postoperative complications were assessed using the Clavien-Dindo classification [13]. Furthermore, two pathologists (MT and SN) determined the histopathological diagnoses (in all patients), which were used to prognosticate future outcomes. The pathological diagnosis made by each of the 2 observers were the same for each patient.

In this study, all operations were performed by a single surgeon (KT). He had experience in operating over 700 and 30 patients using TUR and en-bloc resection (for small masses) techniques, respectively. However, he had no special training in EMR. Therefore, he was verbally guided by a surgeon experienced in colonic EMR during the operative procedures for the first 3 patients.

\section{Follow-up and outcomes}

After TUR, we investigated all patients' cystoscopy and cytology results once every three months for 2 years and then every 3-6 months for 5 years depending on the pathological features. The mean (range) follow-up period of the study population was 26 (9-60) months.

\section{Statistical analyses}

The Mann-Whitney U test was used for comparisons involving continuous variables because of the relatively small number of patients. The chi-square test and Fisher's exact test were used to compare categorical data. All statistical analyses were two-sided and performed using StatView for Windows (version 5.0; Abacus Concepts, Inc., Berkeley, CA, USA) software. $P$ values $<0.05$ were considered representative of statistical significance.

\section{Results}

The tumors in all patients were successfully removed using en-bloc resection, and all extracted specimens were found to include detrusor muscle tissue. The information on the operative procedures is shown in Table 2. 

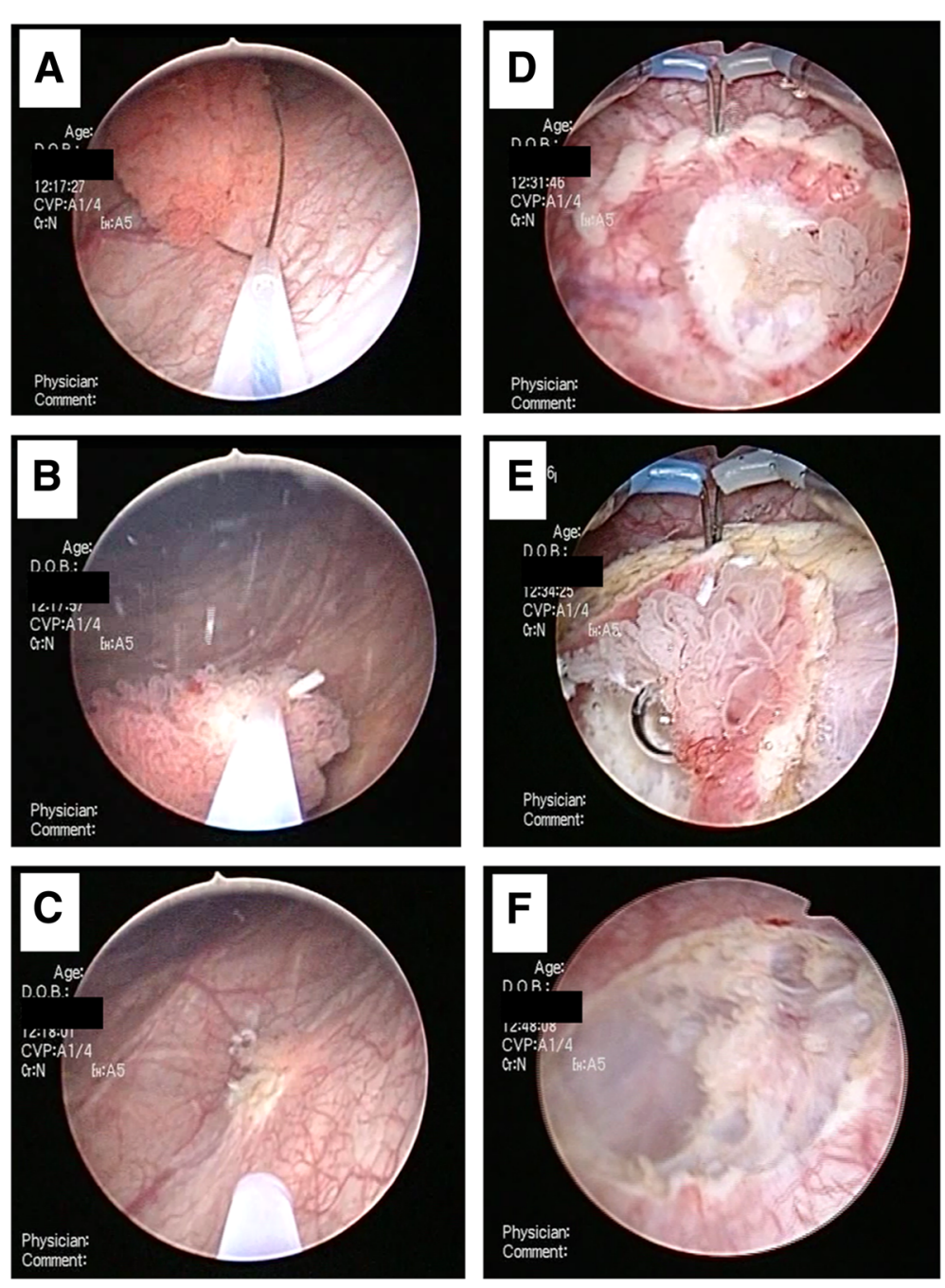

Fig. 1 A description of the surgical technique for performing EMR + en-bloc resection. a A snare is inserted at the base of the pedunculated tumor; $\mathbf{b}$ the snare is placed close to the bottom of the tumor, and EMR is performed; $\mathbf{c}$ a flat or residual tumor mass is shown; $\mathbf{d}$ a circular incision is created around the residual tumor, maintaining a distance of approximately $5-10 \mathrm{~mm}$ from the tumor edge; e en-bloc resection is performed, and $\mathbf{f}$ the tumor is completely resected. (EMR: endoscopic mucosal resection)

Table 2 Information on operation and hospitalization after operation

\begin{tabular}{|c|c|c|c|c|c|c|c|}
\hline & \multicolumn{3}{|c|}{ EMR + En-bloc } & \multicolumn{3}{|c|}{ Transurethral resection } & \multirow[t]{2}{*}{$P$ value } \\
\hline & Mean & SD & Range & Mean & SD & Range & \\
\hline Age; years & 69.7 & 7.7 & $55-86$ & 70.5 & 6.6 & $53-80$ & 0.635 \\
\hline Tumor number & 1.3 & 0.6 & $1-3$ & 1.4 & 0.6 & $1-3$ & 0.458 \\
\hline Tumor size; cm & 2.9 & 0.8 & $1.5-5.5$ & 2.6 & 0.9 & $1.5-5.0$ & 0.120 \\
\hline \multicolumn{8}{|l|}{ Operation time; min } \\
\hline For EMR & 1.6 & 1.1 & $1-5$ & - & - & - & \\
\hline For en bloc & 16.9 & 10.5 & $2-43$ & - & - & - & \\
\hline Total & 18.3 & 10.5 & $3-48$ & 17.3 & 9.5 & $2-31$ & 0.691 \\
\hline Catheterization: days & 4.2 & 2.3 & $3-14$ & 3.7 & 1.4 & $3-10$ & 0.285 \\
\hline Clavien-Dindo score $^{a}$ & $N$ & $\%$ & & $N$ & $\%$ & & 0.881 \\
\hline 1 & 7 & 17.9 & & 6 & 19.4 & & \\
\hline
\end{tabular}

${ }^{\mathrm{a}}$ Overall postoperative complications postoperative day 0-90. EMR: endoscopic mucosal resection 
There were no significant differences in the patients operated using either method, with respect to factors including age at the time of operation, number of tumors, or size of the main lesion. The mean (standard deviation [SD], range) operative periods for EMR and en-bloc resection were $1.6(1.1,1-5) \mathrm{min}$ and $16.9(10.5,2-43)$ min, respectively. The total operative duration for the EMR + en-bloc resection and the TUR groups was 18.3 min $(10.5,3-48)$ and 17.3 min $(9.5,2-31)$, respectively, which was not significantly different between the two groups $(p=0.691)$. The operative time periods needed for the EMR + en-bloc resection of tumors with diameters $\geq 3.5 \mathrm{~cm}$ (28.3\%; $11 / 39$ patients) are shown in Table 3 . While the total operative time for the removal of a 5.5$\mathrm{cm}$ sized tumor was $41 \mathrm{~min}$, the time interval required for EMR was only $2 \mathrm{~min}$. Thus, EMR was completed within $3 \mathrm{~min}$ even for relatively large tumors.

Although the surgeon had no prior experience in EMR, he was able to perform it easily from the first operation, with only verbal guidance. In fact, the median time interval calculated for all EMRs in the 1st-5th, 6th-15th, 16th-30th, 31st-35th, and 36th-39th operated patients, was $2 \mathrm{~min}$. We also show comparative data of the TUR group in Table 3. In the TUR group, 7

Table 3 Operation time in tumor $\geq 3.5 \mathrm{~cm}$

\begin{tabular}{|c|c|c|c|c|}
\hline \multirow{2}{*}{$\begin{array}{l}\text { Local of } \\
\text { tumour }\end{array}$} & \multirow{2}{*}{$\begin{array}{l}\text { Tumour } \\
\text { size; } \mathrm{cm}\end{array}$} & \multicolumn{3}{|c|}{ Operation time; min } \\
\hline & & EMR & En-bloc & Total \\
\hline \multicolumn{5}{|c|}{ EMR + en-bloc } \\
\hline Lateral & 3.5 & 1 & 21 & 22 \\
\hline Dome & 4.0 & 1 & 21 & 22 \\
\hline Posterior & 3.5 & 2 & 42 & 44 \\
\hline Lateral & 4.0 & 3 & 10 & 13 \\
\hline Trigone & 5.5 & 2 & 39 & 41 \\
\hline Dome & 4.0 & 2 & 21 & 23 \\
\hline Lateral & 3.5 & 1 & 16 & 17 \\
\hline Lateral & 3.5 & 1 & 10 & 11 \\
\hline Dome & 3.5 & 2 & 30 & 32 \\
\hline Lateral & 3.5 & 1 & 9 & 10 \\
\hline Dome & 4.0 & 2 & 5 & 7 \\
\hline \multicolumn{5}{|l|}{ TUR } \\
\hline Dome & 3.5 & - & - & 19 \\
\hline Lateral & 4.5 & - & - & 39 \\
\hline Lateral & 3.5 & - & - & 28 \\
\hline Posterior & 5.0 & - & - & 31 \\
\hline Lateral & 3.5 & - & - & 23 \\
\hline Lateral & 3.5 & - & - & 20 \\
\hline Lateral & 4.0 & - & - & 21 \\
\hline$P$ value & 0.826 & - & - & 0.470 \\
\hline
\end{tabular}

EMR endosopic mucosal resection, TUR transurethral resection patients (22.5\%) had tumors with diameters $\geq 3.5 \mathrm{~cm}$, and there were no significant differences in the total operative time periods $(p=0.470)$ required for these patients.

With regard to safety assessment, no severe complications, e.g., acute bleeding, occurred during or after the operation in both the EMR + en-bloc and the TUR groups. None of the patients required a blood transfusion. In the EMR + en-bloc resection group, no patient required conversion to conventional TUR. Although a minor perforation (visible fat tissue) occurred in one patient in the EMR + en-bloc resection group, surgical treatment or peritoneal drainage was unnecessary. Total $7(17.9 \%)$ and 6 patients (19.4\%) in the EMR + en-bloc and TUR groups, respectively, experienced grade $1 \mathrm{com}-$ plications as per the Clavien-Dindo scale. However, no patient had $\geq$ grade 2 complications. The risk of occurrence of complications was found to be similar across both groups $(p=0.881$, Table 2$)$. The mean duration of urinary catheterization in the EMR + en-bloc resection group (mean, 4.2 days; SD, 2.3 days) was also similar to that in the TUR group (mean, 3.7 days; SD, 1.4 days; $p=0.285$ ).

The pathologists were able to determine the invasive status with considerable certainty in all specimens of patients in the EMR + en-bloc resection group. However, both pathologists commented that determining malignant invasion into the bladder submucosal connective tissues was difficult in 6 of the 31 specimens $(19.4 \%)$ of the patients in the TUR group, due to heat denaturation. Statistical analysis showed that this difference in ease of diagnosis between both groups was statistically significant $(p=0.016)$. These 6 patients further underwent a second TUR procedure because their tumors were judged as high grade, with or without pT1 (invasion of lamina propria) disease, though residual cancer cells were not detected in such specimens.

After a mean follow-up of 12 months, 6/39 (15.4\%) and 6/31 (19.4\%) patients in the EMR + en-bloc resection and the TUR groups, respectively, experienced recurrence of the bladder mucosal cancer. Thus, the recurrence rate of NMIBCs was found to be similar across both groups $(p=0.662)$.

\section{Discussion}

We demonstrated that the novel EMR + en-bloc resection technique is safe and useful and enables an accurate pathological diagnosis in $\mathrm{BCs}$, though the operative time period and duration of hospitalization required are similar to those observed with conventional TUR. While en-bloc resection has various advantages with respect to diagnosis and treatment of $\mathrm{BCs}$, as compared to those achieved with conventional TUR, it also has its disadvantages, e.g., prolonged surgical duration. Our novel combined approach aimed to solve this main disadvantage of en-bloc resection. 
There are various opinions on the suitable tumor size and number of lesions that indicate the need for en-bloc resection. Hurle et al. suggested that patients with a single tumor with diameter $<30 \mathrm{~mm}$ and/or those with $<4$ lesions are eligible for en-bloc resection [14]. In another study, tumors $>40 \mathrm{~mm}$ in diameter were excluded [15]. A tumor diameter $>25 \mathrm{~mm}$ has been suggested as a clear contraindication for en-bloc resection [16]. The European Association of Urology guidelines mentioned that small tumors (defined as those with a diameter $<10 \mathrm{~mm}$ ) can be resected en-bloc [8]. Reports within the past 5 years have shown that the mean diameter of tumors operated using en-bloc resection, was between 1.58-2.63 $\mathrm{cm}$, and the operative duration was between 21.46-58.2 min (Table 4). However, the mean tumor size and operative period for our EMR + en-bloc resection technique were $2.90 \mathrm{~mm}$ and $20.0 \mathrm{~min}$, respectively. Based on these results, we suggest that this method can be used to resect tumors more efficiently, as compared with previous en-bloc resection techniques.

Electrical and laser devices have been mainly utilized for en-bloc resection in BCs. After Saito described the utility and safety of laser en-bloc resection of bladder tumors in 2001 [26], other reports have indicated the effectiveness of Ho:YAG or Tm:YAG laser treatment [17-22, 25]. The advantages of en-bloc laser resection include absence of the obturator reflex, minimal intraoperative bleeding, reduced hospitalization period, and lower complications, as compared to conventional TUR [21, 27, 28]. However, laser resection is inferior to electrical resection in terms of availability and medical economics, because, not every hospital has access to laser devices, which also render the treatment expensive. We emphasize that our EMR + enbloc resection method has a relatively low cost and can be used commonly, as it does not require a special device. Therefore, our EMR + en-bloc method can be employed worldwide, even in developing countries.

A metanalysis showed that en-bloc resection can provide high-quality specimens for the pathological diagnosis of BC [29]. Our study supports this finding because the extracted specimens of the EMR + en-bloc resection group were clearly suitable for the pathological diagnosis. The histopathological diagnosis is one of the strongest determinants of treatment alternatives in further management of BCs, e.g., second TUR procedure or intra-vesical therapy. It is also used to determine the post-treatment follow-up schedule. An accurate pathological diagnosis leads to suppression of the overall treatment costs and reduces the mental and physical burden on the affected patient. The novel EMR + en-bloc resection approach can therefore be included, while planning an optimal strategy for the treatment and observation of patients with NMIBC.

To perform en-bloc resection of large, malignant bladder tumors, several investigators have used various modified methods and employed new devices. Naselli et al. retrieved tumors with diameters $\leq 45 \mathrm{~mm}$ using Collins loop and laparoscopic forceps [30], while Frische et al. reported performing en-bloc resection of tumors $\leq 75 \mathrm{~mm}$ in diameter, using a water jet dissector and needle knife for transurethral dissection [31]. Unfortunately, up to $45 \mathrm{~min}$ were needed for tumor resection in the former procedure,

Table 4 A review of literature on en-bloc resection within recent 5 years

\begin{tabular}{|c|c|c|c|c|c|}
\hline Author: device & $N$ & Tumour size; $\mathrm{cm}$ & Tumour number & Operation time; min & Reference/Year \\
\hline \multicolumn{6}{|l|}{ E-ERBT } \\
\hline Kramer: Monopolar & 91 & $2.13(0.71)$ & $1.48(0.74)$ & $27.19(11.96)$ & {$[17] / 2015$} \\
\hline Kramer: Bipolar & 65 & $2.25(0.71)$ & $1.62(0.86)$ & & \\
\hline Hurle & 74 & $1.98(0.59)^{a}$ & $1(1-4)$ & - & {$[14] / 2016$} \\
\hline \multicolumn{6}{|l|}{ L-ERBT } \\
\hline Liu: Thulium YAG & 64 & $1.31(0.23)$ & $2.8(1.2)$ & $48.2(15.8)$ & {$[18] / 2013$} \\
\hline He: Green-light KTP & 45 & $1.8(0.8-3.0)$ & - & $21(12-38)$ & {$[19] / 2014$} \\
\hline Chen: Thulium YAG & 71 & $2.6(1.4)$ & $1.8(1.5)$ & $56.5(37.4)$ & {$[20] / 2015$} \\
\hline Muto: Thulium YAG & 55 & $2.36(1.47)$ & & $33(14)$ & {$[21] / 2015$} \\
\hline Kramer; Holmium YAG & 50 & $2.63(0.79)$ & $1.36(0.56)$ & $29.65(12.46)$ & {$[17] / 2015$} \\
\hline Kramer: Thulium YAG & 15 & $1.66(0.73)$ & $2.60(0.73)$ & & \\
\hline Migliari: Thulium & 58 & $2.5(0.5-4.5)$ & - & $25(12-30)$ & {$[22] / 2015$} \\
\hline Chen: Green-light LBO & 83 & $1.85(1.07)$ & $1.76(0.81)$ & $21.46(10.42)$ & {$[23] / 2016$} \\
\hline Zhang: Vela & 38 & $2.1(0.8-3.0)$ & - & $23(15-43)$ & {$[24] / 2017$} \\
\hline D'souza: Holmium YAG & 27 & $1.58(0.31)$ & $2.5(1.5)$ & $58.2(15.8)$ & {$[25] / 2017$} \\
\hline
\end{tabular}

Data were showed as mean (SD or range)

${ }^{a}$ Among 74 patients, 6 underwent a combination of ERBT and TURBT E-ERBT electrical en-bloc resection of bladder tumor, $L$-ERBT laser en-bloc resection of bladder tumor, YAG Yttrium Aluminum Garnet, KTP potassium-titanyl-phosphate, LBO lithium triborate 
while the authors did not describe the precise operative duration for the latter method. Furthermore, one study evaluated the combined use of electrical en-bloc resection of the tumor (E-EBRT) and TUR to treat patients with NMIBC [13]. In that study, although E-EBRT was performed for single tumor masses $\leq 3 \mathrm{~cm}$ and for those BCs with $\leq 4$ lesions, the en-bloc resection was limited to tumors with $\leq 3$ lesions, and those with diameters $\geq 4 \mathrm{~cm}$ were removed via TUR. However, as shown in Table 3, our EMR + en-bloc resection technique was useful for extracting tumors with diameters $\geq 3.5 \mathrm{~cm}$. Furthermore, with regard to safety and adverse events, no patient operated using our combined approach required conversion to conventional TUR, blood transfusion, or additional surgical procedures, in this study. Thus, we emphasize that our EMR + en-bloc method has some advantages for resection of relatively larger tumors.

A randomized study of 142 patients showed that there was no significant difference in recurrence rates achieved with en-bloc resection and conventional TUR $(p=0.383)$ [20]. In addition, a multicenter European study of 221 patients, supported this finding [17]. Although our study population is relatively small as compared to those in other studies, we also found a comparable rate of recurrence between patients in the EMR + en-bloc resection and the conventional TUR groups. Furthermore, a previous report showed that the recurrence rates after 12 months were 24.5 and $18.5 \%$ for E-EBRT and laser en-bloc resection of the tumor (L-EBRT), respectively [17]. Comparatively, in our study, the recurrence rate observed in the EMR + en-bloc resection group was $15.4 \%$ after 12 months. Thus, the recurrence rate of $\mathrm{BC}$ observed with our en-bloc resection method was similar to, or even better than that achieved with the L-EBRT technique.

The major limitations of this study include its nonrandomized design and the relatively small studypopulation (which also affected collection of follow-up data). However, we believe that our findings are significant as those of a preliminary study, because this is the first report of the utilization of an original, easily adopted, and cost-effective EMR + en-bloc resection technique that may be used effectively in patients with NMIBC. In addition, this operation was performed by a single surgeon in a single institution, and clinicopathological features were matched between the EMR + enbloc and TUR groups. Therefore, biases occurring due to surgical technique and patient background were kept to a minimum. However, another limitation was that the pathologists could not be blinded, as they were able to determine the surgical method employed, from the histopathological characteristics of resected tissues. However, this was a retrospective study and the two pathologists were not made aware of the design and significance of the study when they made the histopathological diagnosis.
Furthermore, another limitation is that the health insurance system in Japan differs from those in other countries. Consequently, certain data, including duration of catheterization, were influenced because their costs were covered by this system, which should be considered during data analysis. However, we believe that the influence of such differences is not that significant on our discussion because they were comparable across both treatment groups. Finally, we recommend that further detailed, large-scale research based on the results of this preliminary study are necessary to determine the safety and usefulness of the EMR + en-bloc resection technique in patients with BC. Long-term clinical studies with inclusion of patients with larger-sized tumors are important to determine and improve upon the efficacy and safety of this original operative approach.

\section{Conclusions}

Our results showed that the novel EMR + en-bloc resection technique is feasible, useful, and safe for treating patients with NMIBC. In addition, an accurate pathological diagnosis can be reached, using this technique. Further large-scale, multicenter, randomized controlled trials with long-term follow-up, are needed to validate our findings and to improve the long-term outcomes in patients with NMIBC.

\section{Abbreviations}

BC: Bladder cancer; E-EBRT: Electrical en-bloc resection of the tumor; EMR: Endoscopic mucosal resection; NMIBC: Non-muscle invasive bladder cancer; TUR: Transurethral resection

\section{Acknowledgements}

None.

\section{Authors' contributions}

Y-H handled project development, participated in the data collection, and undertook writing of the manuscript. Y-M analyzed data and handled project development. T-M, K-O, and H-S participated in data collection. M-T and S-N handled the pathological analysis. K-T performed the procedures and participated in data collection. All authors have read and approved the final manuscript.

\section{Funding}

None.

\section{Availability of data and materials}

All the study data are included in this manuscript.

Ethics approval and consent to participate

This study was approved by the Ethics Committee of the National Hospital Organization Ureshino Medical. Written informed consent was obtained from all the patients involved in our study.

\section{Consent for publication}

All patients enrolled in this study provided written, informed consent for publication of this study.

\section{Competing interests}

The authors declare that they have no competing interests.

\section{Author details}

'Department of Urology, National Hospital Organization Ureshino Medical Center, 2436 Shimosyuku, Ureshino 843-0393, Japan. ${ }^{2}$ Department of 
Urology, Nagasaki University Graduate School of Biomedical Sciences, 1-7-1 Sakamoto, Nagasaki 852-8501, Japan. ${ }^{3}$ Department of Pathology, National Hospital Organization Ureshino Medical Center, 2436 Shimosyuku, Ureshino 843-0393, Japan.

Received: 2 July 2018 Accepted: 17 June 2019

Published online: 24 June 2019

\section{References}

1. Siegel RL, Miller KD, Jemal A. Cancer statistics, 2017. CA Cancer J Clin. 2017; 67(1):7-30. https://doi.org/10.3322/caac.21387.

2. Babjuk M1, Oosterlinck W, Sylvester R, et al. EAU guidelines on non-muscleinvasive urothelial carcinoma of the bladder, the 2011 update. Eur Urol. 2011;59(6):997-1008. https://doi.org/10.1016/j.eururo.2011.03.017.

3. Herr HW, Donat SM. Quality control in transurethral resection of bladder tumours. BJU Int. 2008;102(9 Pt B):1242-6. https://doi.org/10.1111/j.1464410X.2008.07966.X.

4. Zhang KY, Xing JC, Li W, Wu Z, Chen B, Bai DY. A novel transurethral resection technique for superficial bladder tumor: retrograde en bloc resection. World J Surg Oncol. 2017;15(1):125. https://doi.org/10.1186/ s12957-017-1192-6.

5. Engilbertsson $\mathrm{H}$, Aaltonen KE. Björnsson et al. transurethral bladder tumor resection can cause seeding of cancer cells into the bloodstream. J Urol. 2015;193(1):53-7. https://doi.org/10.1016/j.juro.2014.06.083.

6. Kawada T, Ebihara K, Suzuki T, et al. A new technique for transurethral resection of bladder tumors: rotational tumor resection using a new arched electrode. J Urol. 1997;157(6):2225-6.

7. Ukai R, Hashimoto K, Iwasa T, et al. Transurethral resection in one piece (TURBO) is an accurate tool for pathological staging of bladder tumor. Int J Urol. 2010;17(8):708-14. https://doi.org/10.1111/j.1442-2042.2010.02571.x.

8. Babjuk M, Böhle A, Burger M, et al. EAU guidelines on non-muscle-invasive urothelial carcinoma of the bladder: update 2016. Eur Urol. 2017;71(3):44761. https://doi.org/10.1016/j.eururo.2016.05.041.

9. Heitman SJ, Tate DJ, Bourke MJ. Optimizing resection of large colorectal polyps. Curr Treat Options Gastroenterol. 2017;15(1):213-29. https://doi.org/ 10.1007/s11938-017-0131-5.

10. Ono H, Yao K, Fujishiro M, et al. Guidelines for endoscopic submucosal dissection and endoscopic mucosal resection for early gastric cancer. Dig Endosc. 2016;28(1):3-15. https://doi.org/10.1111/den.12518.

11. Ro JY, Ayala AG, el-Naggar A. Muscularis mucosa of urinary bladder. Importance for staging and treatment. Am J Surg Pathol. 1987;11(9):668-73.

12. Tanaka S, Kashida H, Saito Y, et al. JGES guidelines for colorectal endoscopic submucosal dissection/endoscopic mucosal resection. Dig Endosc. 2015; 27(4):417-34. https://doi.org/10.1111/den.12456.

13. Clavien PA, Barkun J, de Oliveira ML, et al. The Clavien-Dindo classification of surgical complications: five-year experience. Ann Surg. 2009;250(2):18796. https://doi.org/10.1097/SLA.0b013e3181b13ca2.

14. Hurle R, Lazzeri M, Colombo P, et al. "En bloc" resection of nonmuscle invasive bladder Cancer: a prospective single-center study. Urology. 2016; 90(4):126-30. https://doi.org/10.1016/j.urology.2016.01.004.

15. Sureka SK, Agarwal V, Agnihotri S, et al. Is en-bloc transurethral resection of bladder tumor for non-muscle invasive bladder carcinoma better than conventional technique in terms of recurrence and progression?: a prospective study. Indian J Urol. 2014;30(2):144-9. https://doi.org/10.4103/ 0970-1591.126887.

16. Lodde M, Lusuardi L, Palermo S, et al. En bloc transurethral resection of bladder tumors: use and limits. Urology. 2003;62(6):1089-91.

17. Kramer MW, Rassweiler JJ, Klein J, et al. En bloc resection of urothelium carcinoma of the bladder (EBRUC): a European multicenter study to compare safety, efficacy, and outcome of laser and electrical en bloc transurethral resection of bladder tumor. World J Urol. 2015;33(12):1937-43. https://doi.org/10.1007/s00345-015-1568-6.

18. Liu H, Wu J, Xue S, et al. Comparison of the safety and efficacy of conventional monopolar and 2-micron laser transurethral resection in the management of multiple nonmuscle-invasive bladder cancer. J Int Med Res. 2013:41(4):984-92. https://doi.org/10.1177/0300060513477001.

19. He D, Fan J, Wu K, et al. Novel green-light KTP laser en bloc enucleation for nonmuscle-invasive bladder cancer: technique and initial clinical experience. J Endourol. 2014;28(8):975-9. https://doi.org/10.1089/end.2013.0740.

20. Chen $X$, Liao J, Chen L, et al. En bloc transurethral resection with 2-micron continuous-wave laser for primary non-muscle-invasive bladder cancer: a randomized controlled trial. World J Urol. 2015;33(7):989-95. https://doi.org/ 10.1007/s00345-014-1342-1.

21. Muto G, Collura D, Giacobbe A, et al. Thulium:yttrium-aluminum-garnet laser for en bloc resection of bladder cancer: clinical and histopathologic advantages. Urology. 2014;83(4):851-5. https://doi.org/10.1016/j.urology.2013.12.022.

22. Migliari R, Buffardi A, Ghabin H. Thulium laser endoscopic En bloc enucleation of nonmuscle-invasive bladder Cancer. J Endourol. 2015;29(11): 1258-62. https://doi.org/10.1089/end.2015.0336.

23. Chen J, Zhao Y, Wang $S$, et al. Green-light laser en bloc resection for primary non-muscle-invasive bladder tumor versus transurethral electroresection: a prospective, nonrandomized two-center trial with 36-month follow-up. Lasers Surg Med. 2016;48(9):859. https://doi.org/10.1002/lsm.22565.

24. Zhang Z, Zeng $\mathrm{S}$, Zhao J, et al. A pilot study of vela laser for en bloc resection of papillary bladder cancer. Clin Genitourin Cancer. 2017;15(3): e311-4. https://doi.org/10.1016/..clgc.2016.06.004.

25. D'souza N, Verma A. Holmium laser transurethral resection of bladder tumor: our experience. Urol Ann. 2016;8(4):439. https://doi.org/10.4103/ 0974-7796.190815.

26. Saito S. Transurethral en bloc resection of bladder tumors. J Urol. 2001; 166(6):2148-50.

27. Zhu $Y$, Jiang $X$, Zhang J, et al. Safety and efficacy of holmium laser resection for primary nonmuscle-invasive bladder cancer versus transurethral electroresection: single-center experience. Urology. 2008;72(3):608-12. https://doi.org/10.1016/j.urology.2008.05.028.

28. Kramer MW, Bach T, Wolters M. Current evidence for transurethral laser therapy of non-muscle invasive bladder cancer. World J Urol. 2011;29(4): 433-42. https://doi.org/10.1007/s00345-011-0680-5.

29. Wu YP, Lin TT, Chen SH, et al. Comparison of the efficacy and feasibility of en bloc transurethral resection of bladder tumor versus conventional transurethral resection of bladder tumor: a meta-analysis. Medicine (Baltimore). 2016;95(45):e5372.

30. Naselli $A$, Introini $C$, Germinale $F$, et al. En bloc transurethral resection of bladder lesions: a trick to retrieve specimens up to $4.5 \mathrm{~cm}$. BJU Int. 2012; 109(6):960-3. https://doi.org/10.1111/j.1464-410X.2012.10982.x.

31. Fritsche HM, Otto W, Eder $F$, et al. Water-jet-aided transurethral dissection of urothelial carcinoma: a prospective clinical study. J Endourol. 2011;25(10): 1599-603. https://doi.org/10.1089/end.2011.0042.

\section{Publisher's Note}

Springer Nature remains neutral with regard to jurisdictional claims in published maps and institutional affiliations.

Ready to submit your research? Choose BMC and benefit from:

- fast, convenient online submission

- thorough peer review by experienced researchers in your field

- rapid publication on acceptance

- support for research data, including large and complex data types

- gold Open Access which fosters wider collaboration and increased citations

- maximum visibility for your research: over $100 \mathrm{M}$ website views per year

At BMC, research is always in progress.

Learn more biomedcentral.com/submissions 